\title{
PROPAGAÇÃO VEGETATIVA DE Piper umbellatum L. (PIPERACEAE) EM FUNÇÃO DE SUBSTRATOS E COMPRIMENTOS DE ESTACAS
}

\author{
Vegetative propagation of Piper umbellatum L. (Piperaceae) as a function of substrates and cuttings length
}

\author{
Erik Nunes Gomes ${ }^{1}$, Diones Krinski ${ }^{2}$
}

\begin{abstract}
${ }^{1}$ Licenciado em Ciências Agrícolas, Doutorando do Programa de Pós-Graduação em Agronomia - Produção Vegetal, Departamento de Fitotecnia e Fitossanitarismo, Setor de Ciências Agrárias, Universidade Federal do Paraná. E-mail: e93gomes@gmail.com.

${ }^{2}$ Licenciado e Bacharel em Ciências Biológicas, Doutor em Zoologia, Professor Adjunto do Departamento de Ciências Biológicas da Universidade do Estado de Mato Grosso, Campus Universitário de Tangará da Serra (UNEMAT/CUTS). E-mail: dioneskrinski@gmail.com.
\end{abstract}

Artigo enviado em 11/12/2016, aceito em 23/01/2017 e publicado em 03/03/2017.

\begin{abstract}
RESUMO - Piper umbellatum L. (Piperaceae) é um subarbusto perene com atividades anti-inflamatórias, analgésicas, antimicrobianas, antitumorais, antioxidantes e dermoprotetoras. A obtenção da matéria-prima para estes fins é restrita ao extrativismo e às pequenas áreas de cultivo devido ao limitado conhecimento agronômico sobre a espécie. Neste sentido, são necessárias investigações referentes a práticas agronômicas, especialmente técnicas adequadas de propagação. O objetivo do presente trabalho foi avaliar diferentes comprimentos de estaca e tipos de substrato na estaquia de P. umbellatum. Para isso, estacas caulinares de 10,15 e $20 \mathrm{~cm}$ de comprimento e diâmetro médio de um centímetro foram preparadas com corte em bisel na base e reto no ápice, sem folhas e contendo ao menos uma gema. Os propágulos foram estaqueados em tubetes com substrato Plantmax ${ }^{\circledR}$ e vermiculita de granulometria fina, e mantidos em casa de vegetação. Após 50 dias da instalação do experimento foi avaliada a porcentagem de estacas enraizadas, mortas, com calos, com brotações, número médio de raízes, comprimento das três maiores raízes, massa fresca de raízes e de brotações. O enraizamento variou de 37,5\% a 60,0\% e não foi verificado interação entre substratos e comprimento das estacas, exceto para massa fresca de raízes e brotações, para as quais, estacas de maior comprimento apresentaram melhor desempenho. O substrato Plantmax ${ }^{\circledR}$ apresentou menor mortalidade, maior porcentagem de estacas com calo, massa fresca de raízes e número de brotações. Neste sentido são indicadas estacas de $20 \mathrm{~cm}$ e utilização de substrato Plantmax ${ }^{\circledR}$ para obtenção de mudas de melhor qualidade.
\end{abstract}

Palavras-chave - Enraizamento. Estaquia. Plantmax ${ }^{\circledR}$. Produção de mudas. Vermiculita.

Abstract - Piper umbellatum L. (Piperaceae) is a perennial underbrush with anti-inflammatory, analgesic, antimicrobial, antitumor, antioxidant and skin protective activities. Obtaining the raw material for these purposes is limited to extrativism and small areas of cultivation due to limited agronomic knowledge about the species. In this sense, investigations are required referring to agronomic practices, especially proper techniques of propagation. The objective of this study was to evaluate different cutting lengths and types of substrate in the cutting of the species. Softwood cuttings of 10, 15 and $20 \mathrm{~cm}$ in length and average one centimeter diameter were prepared a bevel cut on the base and a straight cut on the apex. The cuttings were made without leaves and containing at least one vegetative bud. The propagules were planted in plastic tubes with Plantmax ${ }^{\circledR}$ substrate and fine-grained vermiculite, and maintained in a greenhouse. Fifty days after planting, the percentage of rooted, dead cuttings, cutting with calluses, sprouted cuttings, average number of roots, length of the three major roots and fresh weight of roots and shoots was evaluated. Rooting percentages varied between 37.5 to $60.0 \%$. There was no interaction between substrates and length of the cuttings, except for fresh weight of roots and shoots, for which, plant cuttings of greater length on Plantmax ${ }^{\circledR}$ substrate showed better performance. The Plantmax ${ }^{\circledR}$ substrate showed lower mortality, greater percentage of cuttings with callus fresh weight of roots and number of shoots. Thus, we indicate cuttings with a length of $20 \mathrm{~cm}$ and using Plantmax ${ }^{\circledR}$ substrate for obtaining better quality seedlings.

Key words - Rooting. Cuttings. Plantmax ${ }^{\circledR}$. Seedling production. Vermiculite. 


\section{INTRODUÇÃO}

Espécies da família Piperaceae possuem elevada importância comercial e agronômica devido à utilização como condimentares, ornamentais, alimentícias e emprego na medicina popular (GUIMARÃES; MONTEIRO, 2005). Uma das mais importantes e conhecidas espécies desta família é a pimenta do reino (Piper nigrum L.), largamente utilizada como especiaria na culinária em diversos países (SRINIVASAN, 2007). Outras espécies do gênero Piper são também utilizadas na medicina popular, especialmente no Brasil, e muitas possuem elevada importância devido à comprovadas atividades farmacológicas e/ou produção de óleos essenciais em suas estruturas (GOGOSZ et al., 2012).

A espécie Piper umbellatum L., anteriormente classificada como Pothomorphe umbellata (L.) Miq., é distribuída na América do Sul, América Central, México e Caribe. No Brasil, é nativa em quase todo o país,principalmente do sul da Bahia até Minas Gerais e São Paulo, sendo conhecida popularmente como pariparoba, aguaxima, capeba, malvaísco, malvarisco e lençol-de-santabárbara (LORENZI; MATOS, 2002; MACHADO, 2014). Em 1926, sob a sinonímia de Heckeria umbellata (L.) Kunth, a espécie teve seu uso formalizado na medicina convencional pela inclusão na Farmacopeia Brasileira, recebendo a denominação de pariparoba (SILVA, 1926).

Trata-se de um subarbusto ereto perene, que pode atingir até $2,5 \mathrm{~m}$ de altura. Possui hastes articuladas e providas de nodos bem visíveis. Caracteriza-se por possuir folhas com até $23 \mathrm{~cm}$, cordatas, e pecíolos de $18-24 \mathrm{~cm}$ (LORENZI; MATOS, 2002). Estudos farmacológicos relatam atividade anti-inflamatória e analgésica (PERAZZO et al., 2005), antimicrobiana (SPONCHIADO-JUNIOR et al., 2007), antitumoral (SACOMAN et al., 2008), sedativa (BIOKA; ABENA,1990), antioxidante e dermoprotetora contra raios UVA e UVB, sendo esta última uma das principais aplicações da planta, especialmente na indústria de cosméticos (ROPKE et al., 2005; MAT'TANA et al., 2009).

Considerando a importância econômica da espécie são necessários estudos relativos à práticas agronômicas, uma vez que a obtenção da matéria prima é atualmente restrita ao extrativismo e às pequenas áreas de cultivo sob conhecimento agronômico científico incipiente (MAIAALMEIDA et al., 2011).

A definição de métodos adequados de propagação é um dos aspectos primordiais para a exploração agronômica de espécies vegetais. Uma das técnicas de propagação que apresenta maior viabilidade é a propagação vegetativa via estaquia. Nesse sentido, fazem-se necessários estudos para padronização de procedimentos mais adequados à cada espécie. Mattana et al. (2009) avaliaram a influência do número de gemas nas estacas e três diferentes substratos (areia, solo e uma mistura de solo, esterco, substrato comercial e vermiculita) para a propagação de $P$. umbellatum via estaquia. Os autores recomendam a utilização da mistura avaliada como substrato e estacas com uma gema para a propagação vegetativa da espécie, todavia, relatam valores máximos de $37,5 \%$ de enraizamento.

Assim, são necessários estudos complementares visando alcançar maiores índices de sobrevivência e enraizamento. O substrato comercial e vermiculita figuram entre os produtos mais comuns e acessíveis para a produção de mudas, sendo importante a avaliação dos mesmos no processo de enraizamento de estacas de espécies de interesse.

Outro fator de importância é o comprimento da estaca, pois está relacionado às reservas de carboidratos e auxinas endógenas, que influenciam na sobrevivência, enraizamento e emissão de brotações (PONTES-FILHO et al., 2014). Estacas curtas poderão não dispor das reservas necessárias ao enraizamento, ao passo que as excessivamente longas podem tornar-se mais suscetíveis à desidratação devido à grande superfície exposta ao ambiente e à maior demanda de água para suprir a grande quantidade de tecido vivo (LIMA et al., 2006).

Diante do exposto, o objetivo do presente trabalho foi avaliar o desempenho de estacas caulinares de $P$. umbellatum com diferentes comprimentos utilizando Plantmax ${ }^{\circledR}$ e vermiculita como substratos, visando maior eficiência agronômica na produção de mudas da espécie.

\section{MATERIAL E MÉTODOS}

O material vegetal foi coletado no período da tarde, entre 16 e 17 horas, em uma população natural de $P$. umbellatum em local parcialmente sombreado às margens $\mathrm{da}$ Rodovia Sebastião Ferraz de Camargo Penteado (SP 250), sob as coordenadas $24^{\circ} 31^{\prime} 00,3^{\prime \prime} \mathrm{S}$ e $48^{\circ} 50^{\prime} 28,8^{\prime \prime} \mathrm{W}$ com altitude aproximada de 1050 metros. Os ramos com folhas foram umedecidos e acondicionados em sacos de polietileno pretos para o transporte até casa de vegetação, onde foram mantidas em nebulização intermitente por 12 horas até a confecção das estacas.

O experimento foi conduzido no Departamento de Fitotecnia e Fitossanitarismo da Universidade Federal do Paraná (UFPR), situado a 252 $25^{\prime} 40^{\prime \prime} \mathrm{S}$ e $49^{\circ} 16^{\prime} 23^{\prime \prime} \mathrm{O}$, a uma altitude de $934 \mathrm{~m}$, na cidade de Curitiba/PR. O clima da região, segundo classificação de Köppen, é Cfb temperado úmido com verão ameno, inverno frio e seco, chuvas uniformemente distribuídas durante o ano e ocorrência de geadas severas frequentes(KÖPPEN, 1931).

Estacas caulinares sem folhas foram confeccionadas com corte em bisel na base e reto no ápice, com comprimentos de 10, 15 e $20 \mathrm{~cm}$, correspondentes aos tratamentos. Os propágulos possuíam diâmetro médio de um centímetro, e continham pelo menos uma gema vegetativa cada. Após a confecção, as estacas foram submetidas à lavagem em água corrente por 5 minutos. Os propágulos foram estaqueados em tubetes plásticos de 120 
$\mathrm{cm}^{3}$ de volume, preenchidos com os dois substratos avaliados, substrato comercial Plantmax ${ }^{\circledR}$ e vermiculita de granulometria fina. O substrato Plantmax ${ }^{\circledR}$, largamente utilizado para propagação de espécies medicinais é composto de casca de madeira, vermiculita, turfa e adubo mineral (informações constantes na embalagem do produto), enquanto que a vermiculita é um substrato inerte, também frequentemente utilizado em trabalhos desta natureza. A comparação entre os dois substratos permite avaliar a influência da disponibilidade de nutrientes para o enraizamento adventício das estacas da espécie.

Os tubetes foram dispostos de forma alternada em suportes plásticos com capacidade para 96 tubetes. As estacas foram mantidas em casa de vegetação com nebulização intermitente de 5 segundos a cada 30 minutos até a avaliação do experimento.

O delineamento experimental foi inteiramente casualizado em arranjo fatorial $3 \times 2$ (3 comprimentos de estaca e 2 substratos), com 4 repetições e 10 estacas por parcela, compreendendo 40 estacas por tratamento, totalizando 240 estacas no experimento. Após 50 dias da instalação dos experimentos foi realizada a avaliação da porcentagem de estacas enraizadas, mortas, com calos, com brotações, número médio de raízes, comprimento das três maiores raízes e massa fresca de raízes e de brotações.

Os dados foram submetidos à análise de homogeneidade de variâncias pelo Teste de Bartlett e as médias comparadas pelo Teste de Tukey a 5\% de probabilidade. Foi utilizado o programa estatístico Assistat (SILVA; AZEVEDO, 2009).

\section{RESULTADOS E DISCUSSÃO}

A análise de variância revelou não haver interação significativa entre substratos e comprimento das estacas para as variáveis analisadas, exceto para massa fresca de raízes e de brotações. Avaliando os fatores isoladamente, verificou-se significância do comprimento das estacas para comprimento médio de raízes e massa fresca de raízes e brotações. $\mathrm{O}$ fator substrato apresentou significância para as variáveis de mortalidade, porcentagem de estacas com calo e massa fresca de raízes e brotações (Tabela 1).

O enraizamento variou de 41,3 a $53,8 \%$, enquanto que a mortalidade variou de 8,8 a $21,3 \%$. Houve uma elevada porcentagem de estacas que emitiram brotações, com valores variando de 66,3 a $82,5 \%$. A porcentagem de estacas com calos apresentou variação de 28,1 até 45,8\%, com maiores valores para estacas em substrato comercial Plantmax ${ }^{\circledR}$ (Tabela 2). O número médio de raízes ficou entre 3,1 e 5,3 alcançando maiores valores, apesar de não significativos estatisticamente, nas estacas de $20 \mathrm{~cm}$ em substrato comercial Plantmax ${ }^{\circledR}$ (Tabela 3).

Tabela 1. Resumo da análise de variância para as porcentagens de enraizamento (ENR), mortalidade (MOR), estacas com calos (CAL), estacas com brotações (BROT), número de raízes (NUR), comprimento das três maiores raízes (COMP), massa fresca das raízes (MFR) e massa fresca das brotações (MFB) em relação aos dois tipos de substratos combinados com os três comprimentos de estacas de Piper umbellatum. Curitiba/PR (2016).

\begin{tabular}{|c|c|c|c|c|c|c|c|c|c|}
\hline \multirow{2}{*}{ Fonte de variação } & \multirow[b]{2}{*}{ G.L. } & \multicolumn{8}{|c|}{ Valores de F } \\
\hline & & ENR & MOR & BROT & CAL & NUR & COMP & MFR & MFB \\
\hline Substratos & 1 & $0,56^{\mathrm{ns}}$ & $0,00^{\mathrm{ns}}$ & $1,44^{\mathrm{ns}}$ & $4,69 *$ & $0,20^{\mathrm{ns}}$ & $1,46^{\mathrm{ns}}$ & $9,24 * *$ & $18,35^{* *}$ \\
\hline Comprimentos & 2 & $1,17^{\mathrm{ns}}$ & $1,56^{\mathrm{ns}}$ & $2,47^{\mathrm{ns}}$ & $1,31^{\mathrm{ns}}$ & $2,49^{\mathrm{ns}}$ & $3,58^{*}$ & $5,07 *$ & $5,42 *$ \\
\hline Interação & 2 & $2,02^{\mathrm{ns}}$ & $1,24^{\mathrm{ns}}$ & $2,08^{\mathrm{ns}}$ & $1,09^{\mathrm{ns}}$ & $0,86^{\mathrm{ns}}$ & $0,46^{\mathrm{ns}}$ & $8,38^{* *}$ & $4,61 *$ \\
\hline Resíduo & 18 & - & - & - & - & - & - & - & - \\
\hline C.V. $(\%)$ & & 34,38 & 91,77 & 21,01 & 75,43 & 31,38 & 30,93 & 66,72 & 46,70 \\
\hline
\end{tabular}

**significativo a $1 \%$; *significativo a 5\%; NS: não significativo. C.V.: Coeficiente de Variação.

O comprimento e massas fresca de raízes e brotações foram estatisticamente superiores em estacas de $20 \mathrm{~cm}$ em comparação com as de $10 \mathrm{~cm}$, ambas não diferindo das de $15 \mathrm{~cm}$. Para massa fresca de raízes e brotações o substrato comercial Plantmax ${ }^{\circledR}$ promoveu maiores valores em comparação a vermiculita (Tabela 2).

Em trabalho realizado com a propagação vegetativa de $P$. umbellatum, Mattana et al. (2009) relataram não haver influência do substrato para a porcentagem de enraizamento de estacas da espécie. Os autores buscaram avaliar a ação conjunta do número de gemas na estaca e diferentes substratos, e, de maneira semelhante ao presente trabalho, não foi verificada interação entre os fatores para as variáveis relacionadas ao enraizamento. As porcentagens de enraizamento observadas pelos autores foram inferiores às observadas no presente trabalho, tendo atingido um máximo de $37,5 \%$. As variações na emissão de raízes adventícias podem estar relacionadas aos distintos potenciais genéticos de enraizamento observados em diferentes acessos da mesma espécie e também à sazonalidade. Sousa et al. (2006) verificaram diferenças entre três acessos de Baccharis trimera (Less.) DC. (Asteraceae), quanto ao potencial de enraizamento e taxas de mortalidade. Os autores avaliaram materiais provenientes de diferentes localidades, e justificaram o enraizamento maior de um deles (Acesso Botucatu) devido ao clima do local onde foi coletado ser mais próximo ao da casa de vegetação que o dos outros dois acessos. 
Quanto à sazonalidade, a coleta do material para o presente experimento, realizada no final do mês de dezembro de 2015, pode ter sido um fator importante no bom desempenho observado, uma vez que, segundo Fachinello et al. (1995), estacas coletadas no período de crescimento vegetativo intenso (primavera/verão) apresentam-se mais herbáceas e, de modo geral, mostram maior capacidade de enraizamento, enquanto que estacas coletadas no inverno e outono possuem maior grau de lignificação e tendem a enraizar menos.

A porcentagem de calos observada é um fator interessante e foi significativamente maior em estacas plantadas em Plantmax ${ }^{\circledR}$. Calos são células parenquimatosas resultantes dos novos centros meristemáticos, e sua formação é um processo independente da formação de raízes. A ocorrência simultânea de calos e raízes, deste modo, se explica pelo fato de ambos envolverem o processo de divisão celular e dependerem de condições ambientais favoráveis (HARTMANN et al., 2002).

Como sendo condicionada aos mesmos estímulos ambientais, a presença de calos pode ser um indicativo de condições favoráveis para a rizogênese, destacando melhor potencial de utilização para o substrato comercial Plantmax ${ }^{\circledR}$ em detrimento da vermiculita.

Tabela 2. Valores médios de enraizamento (\%), mortalidade (\%), emissão de brotações (\%), formação de calos (\%), número de raízes (n), comprimento das três maiores raízes $(\mathrm{cm})$, massa fresca das raízes e massa fresca de brotações $(\mathrm{g})$ em estacas de Piper umbellatum L. com três comprimentos e propagadas em dois substratos: Plantmax ${ }^{\circledR}$ e vermiculita. Curitiba/PR (2016).

\begin{tabular}{|c|c|c|c|c|c|}
\hline \multirow{9}{*}{ 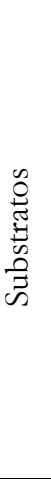 } & Variação & Plantmax $^{\circledR}$ & Vermiculita & \multicolumn{2}{|l|}{ DMS } \\
\hline & Enraizamento (\%) & $50,0 \pm 6,6^{\mathrm{ns}}$ & $45,0 \pm 13,0$ & \multicolumn{2}{|l|}{14,00} \\
\hline & Mortalidade (\%) & $15,8 \pm 3,8^{\mathrm{ns}}$ & $15,8 \pm 11,5$ & \multicolumn{2}{|l|}{12,46} \\
\hline & Brotação (\%) & $76,7 \pm 8,0^{\mathrm{ns}}$ & $69,2 \pm 12,3$ & \multicolumn{2}{|l|}{13,14} \\
\hline & Calos $(\%)$ & $43,8 \pm 12,7 \mathrm{a}$ & $27,8 \pm 11,5 \mathrm{~b}$ & \multicolumn{2}{|l|}{13,74} \\
\hline & Número de raízes (n) & $4,3 \pm 1,1^{\mathrm{ns}}$ & $4,0 \pm 0,4$ & \multicolumn{2}{|l|}{01,12} \\
\hline & Comp. das raízes (cm) & $4,9 \pm 0,7^{\mathrm{ns}}$ & $4,2 \pm 1,0$ & \multicolumn{2}{|l|}{01,22} \\
\hline & M. fresca das raízes (g) & $0,49 \pm 0,38$ a & $0,20 \pm 0,19 \mathrm{~b}$ & \multicolumn{2}{|l|}{0,198} \\
\hline & M. fresca de brotações (g) & $2,50 \pm 1,26 \mathrm{a}$ & $1,05 \pm 0,36 \mathrm{~b}$ & \multicolumn{2}{|l|}{0,710} \\
\hline \multirow{9}{*}{ 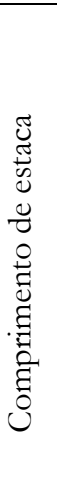 } & Variação & $10 \mathrm{~cm}$ & $15 \mathrm{~cm}$ & $20 \mathrm{~cm}$ & DMS \\
\hline & Enraizamento (\%) & $41,3 \pm 5,3^{\mathrm{ns}}$ & $53,8 \pm 8,8$ & $47,5 \pm 14,1$ & 20,84 \\
\hline & Mortalidade (S) & $21,3 \pm 1,8^{\mathrm{ns}}$ & $8,8 \pm 8,8$ & $17,5 \pm 7,1$ & 18,54 \\
\hline & Brotação (\%) & $66,3 \pm 1,8,4^{\mathrm{ns}}$ & $82,5 \pm 3,5$ & $70,0 \pm 17,6$ & 19,55 \\
\hline & Calos $(\%)$ & $28,1 \pm 1,5^{\mathrm{ns}}$ & $45,8 \pm 8,8$ & $33,3 \pm 23,5$ & 20,46 \\
\hline & Número de raízes (n) & $3,3 \pm 0,4^{\mathrm{ns}}$ & $4,4 \pm 0,0$ & $4,7 \pm 0,8$ & 01,67 \\
\hline & Comp. raízes (cm) & $3,8 \pm 1,1 \mathrm{~b}$ & $4,3 \pm 0,3 \mathrm{ab}$ & $5,7 \pm 0,1$ a & 01,82 \\
\hline & Massa fresca das raízes (g) & $0,16 \pm 0,14 \mathrm{~b}$ & $0,35 \pm 0,09 \mathrm{ab}$ & $0,53 \pm 0,57 \mathrm{a}$ & 0,294 \\
\hline & M. fresca de brotações (g) & $1,18 \pm 0,70 \mathrm{~b}$ & $1,63 \pm 0,34 \mathrm{ab}$ & $2,51 \pm 2,03 \mathrm{a}$ & 1,057 \\
\hline
\end{tabular}

* Médias seguidas pela mesma letra na linha não diferem pelo teste de Tukey $(\mathrm{p}<0,05)$. DMS: Diferença mínima significativa. ns: não significativo.

A interação observada entre substrato e comprimento de estaca, na qual estacas de $20 \mathrm{~cm} \mathrm{em}$ substrato Plantmax ${ }^{\circledR}$ foram superiores às demais para massa de raízes e brotações pode ser explicada pelo efeito conjunto entre a maior quantidade de reservas na estaca e maior disponibilidade de nutrientes. $O$ substrato comercial Plantmax ${ }^{\circledR}$ promoveu maior massa fresca de raízes, fato devido, provavelmente, à disponibilidade de nutrientes, inexistente em vermiculita. Cunha et al. (2015), ao avaliarem o enraizamento de estacas apicais medianas e basais de Piper hispidum Sw. em diferentes substratos relataram maiores valores de massa seca de raízes em substrato solo + esterco de aves, atribuindo à maior disponibilidade de matéria orgânica e nutrientes. Em estudo que avaliou diferentes substratos no enraizamento de cultivares de goiaba (Psidium guajava L.) (Myrtaceae), o substrato Plantmax ${ }^{\circledR}$ e uma mistura de solo areia e matéria orgânica foram superiores para a maioria das variáveis observadas. De acordo com os autores, os resultados superiores do substrato comercial foram atribuídos às suas características físico-químicas, como a presença de matéria orgânica, quantidade suficiente de cargas iônicas, porosidade e retenção de umidade 
satisfatória (ZIETEMANN; ROBERTO, 2007). A elevada porcentagem de estacas com emissão de brotações é um fator relevante a ser observado no presente trabalho. Apesar de necessária para a formação de mudas, a presença de brotações, se excessivamente vigorosas e em grande quantidade, podem mostrar-se indicativos negativos de enraizamento adventício das estacas. Delgado e Yuyama (2010) trabalhando com estaquia de camu-camu (Myrciaria dubia) (Myrtaceae), relataram que a espécie apresenta altos índices de enraizamento pelo fato de apresentar a formação de raízes anteriormente à formação de brotos, priorizando a alocação de nutrientes da estaca para o desenvolvimento radicial e não para brotações. $O$ efeito negativo das brotações, se anteriores à formação das raízes em estacas caulinares, se dá pela ação do hormônio vegetal citocinina, que é gradualmente metabolizado em favor da brotação, direcionando as reservas para processos alheios à formação de raízes, podendo, inclusive, inibir a emissão das mesmas (PASQUAL et al., 1998).

Apesar do tamanho não ter influenciado a sobrevivência das estacas, é provável que estacas com comprimentos maiores do que os avaliados no presente trabalho não sejam vantajosas para a propagação vegetativa desta espécie. Para estacas caulinares de P. umbellatum, Mattana et al.(2009) relacionaram ao comprimento as maiores porcentagens de sobrevivência de estacas com um nó em relação à estacas com dois nós. Estacas com dois nós, com cerca de $25 \mathrm{~cm}$ de comprimento não foram indicadas para a propagação da espécie. De fato, o comprimento excessivo dos propágulos pode prejudicar a sobrevivência, uma vez que estacas longas podem tornar-se mais suscetíveis à desidratação devido à grande superfície exposta ao ambiente e à maior demanda de água para suprir a grande quantidade de tecido vivo (LIMA et al., 2006). É importante ressaltar, no entanto, que no presente trabalho apesar do comprimento das estacas não interferir diretamente na porcentagem de enraizamento e sobrevivência, de modo geral, estacas de $20 \mathrm{~cm}$ se mostraram superiores às de $10 \mathrm{~cm}$ para o comprimento e massa fresca de raízes, indicadores importantes da qualidade e vigor do sistema radicular.

Considerando a interação dos fatores para massa fresca de raízes e brotações, observa-se que, para ambas as variáveis, estacas de $20 \mathrm{~cm}$ em substrato Plantmax ${ }^{\circledR}$ foram superiores às estacas de menor comprimento. No substrato vermiculita não se observou diferença entre os comprimentos (Tabela 3). Este fato está relacionado à quantidade superior de reservas, especialmente carboidratos, presentes em estacas de maiores comprimentos, uma vez que, em estacas sem folhas, as reservas do caule são a fonte de energia para emissão de novas raízes e brotações. Pontes-Filho et al. (2014) relataram maiores comprimentos e massa seca de raízes em estacas de pitaia, (Hylocereus undatus Haw) (Cactaceae), com 17 a $26 \mathrm{~cm}$ em detrimento de estacas menores $(5 \mathrm{a} 14 \mathrm{~cm})$.

Lima et al. (2006), de maneira similar, registraram maiores valores de comprimento de raízes e massa seca de raízes em estacas de aceroleira com $20 \mathrm{~cm}$ em comparação às de $10 \mathrm{~cm}$. Ambos os autores relacionaram os maiores valores com a maior disponibilidade de reservas nas estacas.

Tabela 3. Médias da massa fresca de raízes e das brotações (g) na interação de estacas com diferentes comprimentos de Piper umbellatum L. em dois substratos.

\begin{tabular}{|c|c|c|c|c|}
\hline & \multicolumn{3}{|c|}{ Massa fresca de raízes (g) } & \multirow[b]{2}{*}{ Média } \\
\hline Substrato & $10 \mathrm{~cm}$ & $15 \mathrm{~cm}$ & $20 \mathrm{~cm}$ & \\
\hline Plantmax $^{\circledR}$ & $0,26 \pm 0,07 \mathrm{aB}$ & $0,28 \pm 0,16 \mathrm{aB}$ & $0,93 \pm 0,24 \mathrm{aA}$ & $0,49 \pm 0,38 \mathrm{a}$ \\
\hline Vermiculita & $0,06 \pm 0,05 \mathrm{aA}$ & $0,42 \pm 0,46 \mathrm{aA}$ & $0,13 \pm 0,10 \mathrm{bA}$ & $0,20 \pm 0,19 \mathrm{~b}$ \\
\hline \multirow[t]{2}{*}{ Média } & $0,16 \pm 0,14 \mathrm{~B}$ & $0,35 \pm 0,09 \mathrm{AB}$ & $0,53 \pm 0,57 \mathrm{~A}$ & \\
\hline & \multicolumn{3}{|c|}{ Massa fresca de brotações (g) } & \\
\hline Substrato & $10 \mathrm{~cm}$ & $15 \mathrm{~cm}$ & $20 \mathrm{~cm}$ & Média \\
\hline Plantmax $^{\circledR}$ & $1,67 \pm 0,79 \mathrm{aB}$ & $1,87 \pm 1,22 \mathrm{aB}$ & $3,95 \pm 1,18 \mathrm{aA}$ & $2,50 \pm 1,26 \mathrm{a}$ \\
\hline Vermiculita & $0,68 \pm 0,21 \mathrm{aA}$ & $1,39 \pm 0,37 \mathrm{aA}$ & $1,08 \pm 0,64 \mathrm{bA}$ & $1,05 \pm 0,36 \mathrm{~b}$ \\
\hline Média & $1,18 \pm 0,70 \mathrm{~B}$ & $1,63 \pm 0,34 \mathrm{AB}$ & $2,51 \pm 2,03 \mathrm{~A}$ & \\
\hline
\end{tabular}

*Médias seguidas pela mesma letra maiúscula nas linhas e minúscula nas colunas não diferem entre si pelo teste de Tukey a $5 \%$ de probabilidade.

Para estacas caulinares da espécie aromática, Ocimum selloi Benth. (Lamiaceae), de maneira semelhante, não foi constatada diferença estatística para a porcentagem de enraizamento e sobrevivência em estacas com diferentes comprimentos, todavia estacas de maior comprimento promoveram valores superiores na biomassa de folhas e raízes (COSTA et al., 2007).
Correia (1998), também relata que estacas de maior comprimento na espécie medicinal, Solidago chilensis Meyen. (Asteraceae), apresentaram maiores reservas nutritivas, o que garantiu a sobrevivência nas fases iniciais de desenvolvimento.

É sabido que maiores teores de carboidratos estão relacionados ao maior vigor do sistema radicular de mudas oriundas de estaquia devido ao fato da auxina requerer uma fonte de carbono para biossíntese de ácidos nucleicos e proteínas (FACHINELLO et al., 1995). Nesse sentido, é 
importante que se encontre um equilíbrio no tamanho das estacas de modo que, possuam uma quantidade de reservas suficientes para garantir emissão e vigor de raízes e brotações, sem, no entanto, comprometer a sobrevivência dos propágulos. Considerando este aspecto, estacas de 20 $\mathrm{cm}$ se mostraram adequadas ao enraizamento nas condições em que este experimento foi realizado.

\section{CONCLUSÕES}

É viável a propagação de $P$. umbellatum por estaquia. $O$ comprimento das estacas não influenciou diretamente o enraizamento, todavia, estacas de $20 \mathrm{~cm}$ obtiveram maior comprimento e massa fresca de raízes em relação às de $10 \mathrm{~cm}$, o que pode ser um indicativo de mudas de melhor qualidade. Da mesma maneira, o substrato comercial Plantmax ${ }^{\circledR}$ é indicado por apresentar incrementos na massa fresca de raízes e brotações e, por ser fonte de nutrientes, possibilitar um maior tempo de permanência das mudas em casa de vegetação, sem necessidade de transplante.

\section{AGRADECIMENTOS}

Os autores agradecem à Coordenação de Aperfeiçoamento de Pessoal de Nível Superior, pelo apoio e bolsas concedidas, ao Biólogo Bruno Felipe Camera (UNEMAT/Tangará da Serra-MT) pelo auxílio na coleta e confecção das estacas e ao professor Dr. Cícero Deschamps (UFPR/Curitiba-PR) pela disponibilização do substrato comercial e vermiculita utilizados no experimento.

\section{REFERÊNCIAS}

BIOKA, D.; ABENA, A. Psychopharmacologic profile of an aqueous extract of Piper umbellatum. Encephale, v.16, p. 205-208, 1990.

CORREIA, E. Aspectos da propagação sexuada e vegetativa da arnica brasileira (Solidago chilensis Meyen. Asteraceae). In: MING, L.C. et al. Plantas medicinais, aromáticas e condimentares: avanços na pesquisa agronômica. Botucatu: UNESP, 1998. Cap. 2, p.193-208.

COSTA, L. C. B.; PINTO, J. E. B. P.; BERTOLUCCI, S. K. V. Comprimento da estaca e tipo de substrato na propagação vegetativa de atroveran. Ciência Rural, v. 37, n. 4, p. 1157-1160, 2007.

CUNHA, A. L. B.; CHAVES, F. C. M.; BATISTA, A.C.; HIDALGO, A. F. Propagação vegetativa de estacas de Piper bispidum Sw. em diferentes substratos. Revista Brasileira de Plantas Medicinais, v. 17, n. 4, supl. 1, p. 685-692, 2015.
DELGADO, J.P.M.; YUYAMA, K. Comprimento de estaca de camu-camu com ácido indolbutírico para a formação de mudas. Revista Brasileira de Fruticultura, v. 32, n. 2, 2010 .

FACHINELLO, J. C.; HOFFMANN, A.; NACHTIGAL, J. C.; KERSTEN, E.; FORTES, G. R. L. Propagação de plantas frutiferas de clima temperado. 2.ed. Pelotas: UFPEL, 1995. 178p.

GOGOSZ, A. M.; BOEGER, M. R. T.; NEGRELLE, R. R. B.; BERGO, C. Anatomia foliar comparativa de nove espécies do gênero Piper (Piperaceae). Rodriguésia, v. 63, n. 2, p. 405-417, 2012.

GUIMARÃES, E. F.; MONTEIRO, D. Piperaceae na reserva biológica de Poço das Antas, Silva Jardim, Rio de Janeiro, Brasil. Rodriguésia, v. 3, n. 57, p. 567-587, 2005.

HARTMANN, H.T.; KESTER, D.E.; DAVIES JR, F.T.; GENEVE, R.L. Plant propagation: principles and practices. 7. ed. New Jersey: Prentice Hall, 2002. 880 p.

KÖPPEN, W. Grundriss der klimakunde. Berlin: W. Guyter, 1931. 390p.

LIMA, R. L. S.; SEVERINO, L. S.; PEREIRA, W. E.; LUCENA, A. M. A.; GHEYI, H. R.; ARRIEL, N. H. C. Comprimento de estacas e parte do ramo na formação de mudas de aceroleira. Revista Brasileira de Fruticultura, v.28, n.1, p.83-86, 2006.

LORENZI, H.; MATOS, F. J. A. Plantas medicinais no Brasil: nativas e exóticas. 2. ed. Nova Odessa: Instituto Plantarum, 2002.

MACHADO, R.D. Desenvolvimento tecnológico e caracterização de extratos vegetais obtidos a partir das raizes de Piper umbellatum $L$. (Piperaceae). 2014. 43f. Dissertação (Mestrado em Ciências Farmacêuticas) - Faculdade de Farmácia da Universidade Federal de Goiás, Goiânia, 2014.

MAIA-ALMEIDA, C.I.; CAVARIANI, C.; OLIVEIRA, P.F.C.; MING, L.C.; MATTANA, R.S.; LIMA, L.P. Revista Brasileira de Plantas Medicinais, Botucatu, v. 13, n. 1, p. 116120, 2011.

MATTANA, R.S.; FRANCO, V.F.; YAMAKI, H.O; MAIA E ALMEIDA, C.I.; MING, L.C. Propagação vegetativa de plantas de pariparoba [Pothomorphe umbellata (L.) Miq.] em diferentes substratos e número de nós das estacas. Revista Brasileira de Plantas Medicinais, v.11, n.3, p.325329, 2009.

PERAZZO, F.F.; SOUZA G.H.; LOPES, W.; CARDOSO, L.G.; CARVALHO, J.C.; NANAYAKKARA， N.P.; 
BASTOS, J.K. Antiinflammatory and analgesic properties of water-ethanolic extract from Pothomorphe umbellata (Piperaceae) aerial parts. Journal of Ethnopharmacology, v.99, p.215- 220, 2005.

PASQUAL, M.; RAMOS, J. D.; HOFFMANN, A.; CARVALHO, G. R. Cultura de Tecidos Vegetais: Tecnologias e aplicaçoes: meios de cultura. Lavras: FAEPE/ UFLA, 1998. 116 p.

PONTES FILHO, F. S. T.; ALMEIDA, E. I. B.; BARROSO, M. M. A.; CAJAZEIRA, J. P.; CORRÊA, M. C. M. Comprimento de estacas e concentrações de ácido indolbutírico (AIB) na propagação vegetativa de pitaia. Revista Ciência Agronômica, v. 45, n. 4, p. 788-793, 2014.

ROPKE, C.D.; SAWADA, T.C.; DA SILVA, V.V.; MICHALANY, N.S.; DE MORAES BARROS, S.B. Photoprotective effect of Pothomorphe umbellata root extract against ultraviolet radiation induced chronic skin damage in the hairless mouse. Clinical and Experimental Dermatology, v.30, p.272-276, 2005.

SACOMAN, J.L.; MONTEIRO, K.M.; POSSENTI, A.; FIGUEIRA, G.M.; FOGLIO, M.A.; CARVALHO, J.E. Cytotoxicity and antitumoral activity of dichloromethane extract and its fractions from Pothomorphe umbellata. Brazilian Journal of Medical and Biological Research, v.41, n.5, p.411-415, 2008.

SILVA, F. A. S.; AZEVEDO, C. A. V. Principal Components Analysis in the Software Assistat-Statistical Attendance. In: World Congress on Computers in Agriculture, 7, Reno-NV-USA: American Society of Agricultural and Biological Engineers, 2009.

SILVA, R. A. D. Pharmacopeia dos Estados Unidos do Brasil. São Paulo: Cia Ed. Nacional, 1926.

SOUSA, L.A.; SACRAMENTO, L.V.S.; MING, L.C. Propagação por estaquia de três acessos de Baccharis trimera em fenofase reprodutiva. Revista Brasileira de Plantas Medicinais, v.8, n.4, p.189-192, 2006.

SPONCHIADO JR, E.C.; PEREIRA, J.V.; PEREIRA, J.O.; FRANCA, S.C. Pothomorphe umbellata (Caapeba), Revista Fitos, v.3, n.2, p.31-37, 2007.

SRINIVASAN, K. Black Pepper and its pungent principlepiperine: A review of diverse physiological effects. Critical Reviews in Food Science and Nutrition, v. 47, n.1, p. 735-748, 2007.

ZIETEMANN, C.; ROBERTO, S.R. Efeito de diferentes substratos e épocas de coleta no enraizamento de estacas herbáceas de goiabeira, cvs. paluma e século XXI. Revista Brasileira de Fruticultura, v.29, n.1, p.31-36, 2007. 